\title{
O constrangimento do ser e a alienação existencial como hipóteses Fenomenológico-Existenciais para o ato de suicidar-se
}

Maira Maria da Costa ${ }^{1}$

Rosina Forteski

\section{Resumo}

Na sociedade atual, na qual a morte é um tabu e deve ser evitada, o suicídio é visto como uma violação de normas sociais. Ao julgar o suicida como transgressor e negar a possibilidade da morte, há uma condenação absoluta à vida, o fato de escolher morrer é uma conduta que recebe reprovação. Este artigo se propõe a elaborar uma compreensão do fenômeno suicídio, considerando o ser na sociedade e a alienação das possibilidades de existência autêntica do homem, embasando-se no pensamento de Heidegger e Sartre. Conclui-se que a Fenomenologia Existencial busca compreender o suicídio a partir do indivíduo, de sua existência, de suas relações no mundo. A aproximação compreensiva do ato de suicidar-se, aqui representada pelo enfoque Fenomenológico-Existencial, é uma maneira legítima de desvelar o fenômeno.

Palavras-chave: Suicídio; Heidegger; Jean-Paul Sartre; Liberdade; Existência.

\section{The embarrassment of being and the existential alienation as Existential-phenomenological assumptions to the act of suicide}

\begin{abstract}
In today's society, in which death is taboo and should be avoided, suicide is seen as a violation of social norms. In judging the suicidal as transgressor and deny the possibility of death there is an absolute condemnation to life, the fact of choosing to die is a conduct that is disapproved. This article aims to develop an understanding of the suicide phenomenon, considering the person in society and the alienation of the possibility of authentic existence of men, basing on Heidegger and Sartre thought. We conclude that Existential-phenomenological approach understands the suicide from the person, its existence and its

\footnotetext{
${ }^{1}$ Psicóloga pela Fameg Uniasselvi. E-mail: mairacosta@hotmail.com

${ }^{2}$ Psicóloga, mestranda em Educação pela Universidade Federal do Paraná. E-mail: rsforteski@gmail.com
} 
relationships in the world. A comprehensive approach to the suicidal action, represented here by Existential-phenomenological approach, it's a legitimate way of unveiling this phenomenon.

Keywords: Suicide; Heidegger; Jean-Paul Sartre; Liberty; Existence.

\section{Introdução}

Atualmente existe uma pluralidade de leituras ora complementares, ora divergentes, do ato de suicidar-se. Angerami-Camon (1986) sustenta uma compreensão do fenômeno como manifestação individual representativa de padrões destrutivos cristalizados pela própria sociedade que se mostra destrutiva, pois nela a violência alcança preocupantes níveis de delírio que revelam não menos que uma manifestação suicida inerente às suas características.

Uma breve escavação na história em torno do tema já denuncia uma tendência da sociedade de tomar para si a responsabilidade de atribuir sentido ao ato de suicidar-se de acordo com condicionantes internos de seu funcionamento econômico, cultural e religioso. Segundo Mello (2000), é possível encontrar no decorrer da história iniciativas tanto de reprovação como de glorificação do suicídio uma vez que a morte tem sido percebida sob diversos prismas: silêncio absoluto, o sono em vida ou ainda o meio para alcançar tanto o inferno quanto o paraíso. Esta ambiguidade também emerge no âmbito pessoal por meio da impossibilidade de se conhecer o momento posterior ao ato e dos questionamentos sobre as suas consequências (levará a Deus ou ao inferno?). Percebe-se, portanto e ainda, que esta atribuição, este apropriar-se dos significantes, caminha para um embate dialético no qual o indivíduo também partilha seus sentidos mais próprios para a edificação das compreensões possíveis.

Ainda assim, se falarmos em termos mais gerais, o suicídio assume hoje características de marginalidade, tendo sido levado a cabo secretamente e sem testemunhas. Essa evidência denuncia a categorização do ato de suicidar-se como violação de normas sociais impostas pelo sistema capitalista, para o qual a morte é um tabu, devendo ser evitada, abolida. Esse julgamento do suicida como transgressor é legitimado pelas vigências culturais de cada sociedade, pois aceitar que alguém possa estar disposto a tirar a própria vida pode significar o desmoronamento da onipotência humana apregoada, a abertura 
para a morte é então negada e a cultura da vida exultada (Sampaio \& Boemer, 2000). Tem-se então uma condenação absoluta à vida, na qual as situações de existência do homem não representam condicionais relevantes para o ato de esquivar-se de sua vivência e de executar a escolha última do livre arbítrio.

O caso de Ellen West, descrito e analisado minuciosamente por Binswanger (1977), é um clássico na área e nos fornece uma representação valiosa da temática. $\mathrm{O}$ autor delineia as agruras vividas por uma mulher presa a uma saga de vida permeada pelo conflito entre o impulso de comer e a aversão ao ganho de peso. A leitura feita por Binswanger desenha a trajetória de Ellen diante de um vazio que lhe invadia após as refeições. O relato do caso denuncia a inautenticidade de sua existência, pois Ellen vê tolhidas suas tentativas de autonomia. Nesse sentido, o suicídio emerge enquanto possibilidade libertadora, que dá acesso ao nada e traz promessas de alívio desta existência. A aniquilação foi então ao encontro das necessidades que fragilizavam e tornavam seu movimento existencial um tormento, levando Ellen a cometer suicídio (Moreira, Cruz \& Vasconcelos, 2005).

Numa tentativa de transpor o foco para indivíduo e sua existência, a Fenomenologia Existencial buscará compreender o suicídio de maneira mais ampla e desmistificada. Assim, para Angerami-Camon (1986), como o suicídio carrega em seu bojo a representação máxima da violência, podendo talvez ser considerado o ato mais degradante de todos, ele acaba por delatar toda a extensibilidade da angústia e do sofrimento do homem moderno. Sampaio e Boemer (2000) descrevem o fenômeno do suicídio como uma situação experienciada pelo ser que não consegue mais visualizar possibilidades para continuar sendo dentro das condições de existência nas quais ele se encontra.

Este artigo se propõe a elaborar uma compreensão do fenômeno suicídio, considerando o ser na sociedade e a alienação das possibilidades de existência autêntica do homem, embasando-se no pensamento de Heidegger e Sartre. Para tanto, são discutidos alguns dos principais fundamentos fenomenológicos dos autores citados, desvelando suas noções de morte, existência, liberdade e angústia como categorias essenciais de análise para a compreensão do ato de suicidar-se.

\section{Heidegger: a morte e o constrangimento do ser}

A concepção de homem de Heidegger demanda que empreendamos uma breve jornada pelos seus questionamentos em uma tentativa de capturar a 
existência pela perspectiva de sua noção de dasein e confrontá-los com o constrangimento ao qual o suicida é exposto diante da complexidade de sua condição existencial. Marques (2010, p.130) assim se refere ao dasein heideggeriano: "ser é, então, ser-em (um mundo). Sempre que digo "eu sou" digo, tacitamente, a minha copertença a esse mundo em que sou". No mesmo sentido, Figueiredo (2003) conceitua este ser aí heideggeriano como metáfora de uma relação gênica entre o sujeito e seu mundo, a saber, este será o mundo que o próprio dasein projeta como campo de suas possibilidades existenciais.

Entrementes, no decorrer de sua autoconstituição temporal, como nos relata Marques (2010), o dasein pode assumir uma existência alheia a si mesmo, sendo aquele que ele não é, frustrando-se e perdendo-se daquilo que lhe é próprio. Ocorre, porém, que se aquele que ele próprio é apreende "os outros" partindo de um processo de indiferenciação, resultando num coletivo impessoal que descreve todos aqueles que são aí comigo, sucumbe-se ao "eles", ao das Man. Logo, é nesta concepção de exterioridade da existência, aqui conceituada pela estrutura das Man, que a possibilidade de alienação e constrangimento do ser e de uma vivência inautêntica se fazem férteis e prováveis.

Se nos permitimos revelar o ato do suicídio como expressão singular da realidade vivencial do homem (Angerami-Camon, 1986) podemos transcender as variáveis tendenciosas que descrevem a composição de um indivíduo médio e compreender as limitações singulares deste ser desistente da vida. Feijoo (2002) nos fala sobre os perigos contingentes ao sujeito que se perde nos limites da impessoalidade, ao sujeito cujo modo vivencial passa a ser ditado pelo mundo. Pois, nesse caso, o mundo das possibilidades passa a ser a vivência do "É": nela o sujeito é o que o mundo lhe designa, "É" representa a conformidade das grandes massas. Nesse perder-se no impróprio, no inautêntico, a liberdade de escolha é marginalizada pelo esquecimento e as possibilidades são restringidas por esses limites de abertura que por sua vez são suscitadas pelo das Man.

Atrelados às abstrações da alienação do ser pela estrutura do das Man alcançamos então os pilares da existência inautêntica. Para Moreira, Cruz e Vasconcelos (2005), a existência inautêntica pode ser descrita como um estado de esvaecimento e desamparo que empurra o ser-aí para a mediocridade, inoculando as expressões singulares de seu existir, perdendo-se no coletivo, entre os outros daseins, e justificando seus atos pela exteriorização de si. Esse homem age em conformidade com padrões, ordens e proibições sem demonstrar indícios de criticidade, pois sua subjetividade está rebaixada e responde a comandos sem questionar seus critérios. Em contraponto, a existência autêntica seria a noção aceita de responsabilidade pessoal, de ser-se um ser sempre em processo, infindável e passível de transcender a situação e a 
realização, aceitando o passado, percebendo o presente e superando-os frente a um novo projeto (Figueiredo, 2003). A insegurança e a fragilidade do ser em abandono para empreender escolhas que caracterizem sua existência como autêntica revelam a periculosidade e a beligerância deste modo de ser do homem que, esmagado pelo estreitamento de suas possibilidades, se percebe indo com a correnteza do coletivo alienado.

Assim, o existir, do ponto de vista Fenomenológico-Existencial, transcende a constatação óbvia do mundo concreto e "pressupõe estar sujeito a, estar entregue a possibilidades factuais que podem ocorrer independentemente do homem desejá-las ou não; é assim que o aí se mostra ao ser" (Sampaio \& Boemer, 2000, p. 330). Ora, na inobservância das condições aviltantes e cerceadoras que constrangem o sujeito e o impedem de viver esta abertura, não estaremos nós a permitir o sufocamento e a impossibilidade do dasein, nos tornando cúmplices com o restringir e o extinguir de suas peculiaridades? A respeito da compreensão do processo saúde/doença sob uma leitura Fenomenológico-Existencial, Feijoo (2002, p. 154) nos recorda que desde muito Heidegger já conceituara, em seu seminário Zollikonner, "a patologia como distúrbio da liberdade e da flexibilidade do homem singular", trazendo à tona uma discussão que abarcava o sujeito como ser de ação, escolhas e consequentes responsabilidades. Destarte, percebe-se aí, nessa constatação ontológica, suscitadas e reunidas as incógnitas do processo de adoecer.

A angústia, no pensamento heideggeriano, é possibilidade rara e tem potencialidade de abrir espaço para a autenticidade. É pela angústia que a finitude existencial humana é percebida e esta noção traz à tona o conceito de ser-para-a-morte de Heidegger. Eis que, dentro da amplitude do poder-ser originário do dasein, o homem se depara com uma limitação: a morte. Ainda assim, esta morte pode ser percebida enquanto parte da existência, e não como encerramento dela, afinal, a morte é sentida "pelos que ficam" (Werle, 2003). Esta percepção da morte enquanto possibilidade que individualiza a experiência humana convida à existência autêntica, e, nessa trilha de pensamento, a sua antecipação pelo suicídio evidencia o estreitamento dos movimentos deste ser no espaço de tempo natural que se coloca entre o agora e o momento da morte.

O horizonte de possibilidades que se mostra ao homem é onde sua existência se constrói, uma vez que todo homem é um projeto de vir-a-ser. Nesse cenário, a morte surge como única certeza possível definindo-o como um ser-para-a-morte. Essa ciência da finitude é o que o singulariza das demais criaturas, no entanto, se o ser-para-a-morte escolher não-mais-ser-aí, remetendo-o à morte, esse ato suicida consiste na negação do curso natural ao ser (Sampaio \& Boemer, 2000). A morte representa uma certeza que repousa em 
um futuro sem data, o ato do suicídio denuncia a invasão do homem no processo natural de desenvolvimento do ser, sufocado pelo seu esvaziamento.

A noção heideggeriana de morte assume, conforme exposição de Araújo (2007, p. 12), perspectivas antropocêntricas, nesse sentido é na morte enquanto abertura e premissa de um existir que o momento da autenticidade se mostra e, na ciência dessas possibilidades, ocorre um movimento interno para a unificação temporal do sujeito no qual "o homem se realiza como si mesmo, como um 'ser íntegro' (Ganzsein) e constitui uma temporalidade com a qual se instaura a condição para seu operar na história". Diante do exposto, alvitra-se o desdobramento de que o ser constrangido pela estreiteza de suas condições existenciais pode tornar-se desistente da vida, pois se vê violado na sua singularidade.

Compreender o tentador de suicídio pelo prisma FenomenológicoExistencial heideggeriano, conforme sugere Sampaio e Boemer (2000), significa optar por uma análise que contempla a sua situacionalidade. A Daseinsanalyse, ou análise da existência, figura enquanto método compreensivo capaz de possibilitar uma aproximação com as particularidades da existência do ser-aí, particularidades estas que se compõem de projetos, angústias e expectativas. Em seu ensaio, os autores propõem que a Daseinanalyse constitui-se como uma possibilidade no processo de atenção em saúde aos suicidas em potencial ou aos indivíduos que já atentaram contra a própria vida de forma voluntária.

\section{Uma leitura sartriana: o ser, liberdade e angústia}

A liberdade é inerente à existência e está ligada à saúde e ao adoecimento existencial. Conforme comenta Forghieri (2004), a saúde existencial se caracteriza pela vivência global da liberdade, acolhimento e sintonia em relação a si, aos outros e ao mundo em geral. A pessoa saudável dispõe livremente das condições de relação com seu mundo de possibilidades. Já o adoecimento existencial se caracteriza pela contrariedade e angústia, provinda de uma vivência global de impotência, insatisfação consigo mesmo, com a própria vida e com os outros, por revolta, apatia e conformismo pessimista. O sofrimento surge quando a pessoa perde a capacidade de decidir livremente sobre suas possibilidades.

A saúde e o adoecimento existencial são parte da vida, são constituintes da totalidade da existência que se alternam constantemente durante a 
existência, às vezes chegando a ser muito próximos, assim construímos conhecimento acerca do mundo e de nós mesmos (Forghieri, 2004).

A existência individual é caracterizada pela escolha autêntica do ser que se escolhe a si-mesmo e, a partir de um processo de constante mutação, constrói seu destino. O sujeito é um ser consciente, apto a fazer escolhas livres e intencionais, dessas escolhas é que resulta o sentido de sua existência, é sua maneira de escolher estar-no-mundo (Teixeira, 2006).

O conceito de autenticidade reflete em aceitar a condição humana como ela é vivida e conseguir confrontar-se com as escolhas e a liberdade de escolher envolve a responsabilidade por fazer seu próprio destino. $\mathrm{O}$ sujeito é o que escolhe ser, sua identidade e características são consequências de suas próprias escolhas. A pessoa, conforme busca conhecer-se, compreender-se e descobrir-se na relação com o outro, constrói o seu mundo, dando sentido à sua existência e escolhendo viver da melhor maneira. $\mathrm{O}$ sujeito busca dar sentido à sua própria existência, e essa busca será sempre inacabada (Teixeira, 2006).

A consciência de "quaisquer coisas" envolve toda a existência e é geradora de conflitos. Segundo Teixeira (2006), existir envolve a consciência de tragédia inerente à condição humana, constituída pela insegurança, frustração e perdas irreparáveis e envolve também a consciência da esperança, que deriva da liberdade de escolha, da auto-realização, da dignidade individual, do amor e da criatividade. A existência é permeada pela consciência de morte, que se traduz na possibilidade do fim de todas as possibilidades, aqui surge o medo da morte, que emerge do conflito entre a consciência de morte e o desejo de continuar sendo; pela consciência da liberdade, que engloba a experiência de responsabilidade e autonomia nas escolhas, que reflete em medo do incerto e do desconhecido; pela consciência da solidão, que implica a experiência de isolamento, medo da separação; pela consciência da falta de sentido, a experiência do vazio e desespero, ao absurdo de existir. Há conflito entre a falta de sentido e o projeto futuro, em contraste há coragem, capacidade para continuar em direção ao futuro, mesmo diante do desespero. O sujeito não pode escolher as limitações de sua existência, mas escolhe como confrontá-las. A negação da liberdade de escolha e/ou negação das limitações implica na negação da possibilidade de escolher livremente o futuro, a isto Sartre conceitua "má fé".

A respeito do ser, Sartre afirma que não se tem que distinguir no existente uma aparência acessível à observação e algo escondido atrás dela, como se houvesse uma divisão. O Ser é exatamente aquilo que o existente mostra, é a realidade completa. O Ser é ser-em-si e ser-para-si. O ser-em-si é o sentido do ser da existência, entrelaçado no fenômeno e revelado pela 
consciência. O ser-para-si é o ser dotado de consciência, em oposição ao ser objeto. Em relação à consciência, ela sempre será consciência de alguma coisa. A consciência não pode ser entendida como constitutiva do ser do objeto, ela é anterior à experiência, é transcendente. O nada surge na presença do conhecido, que não é presente a nada. O nada é a própria realidade humana, ele estabelece a condição para que haja um mundo e a realidade humana se apresenta ao mesmo tempo como posição e negação do mundo (Silva, 1997).

Perante o nada sempre há questionamento, se sabe sobre o ser, mas o não-ser também está presente e é responsável por incertezas. De acordo com Silva (1997), o nada aparece sempre que questionamos sobre o ser, pois as respostas englobam alguma limitação e parte do que algo não é. Descobrimos que permanecemos em meio a negações e é a possibilidade do não-ser, fora de nós e em nós mesmos, que direciona as questões sobre o ser.

O que alguém é depende, em si mesmo, do que ele ainda não é, e o que ele ainda não é depende do que ele já é. Se é o próprio futuro, focando no nãoser. Por isso, é através do homem que o nada vem ao mundo, e para que isto aconteça o homem deve ser livre, deve manifestar o seu ser-em-si, não o não-ser (Silva, 1997). O homem, em seu próprio ser, é livre. A liberdade é fundamento de todas as essências, o homem livremente decide sua vida e assume as responsabilidades de suas escolhas. A liberdade é o determinante da condição humana, o que estrutura o homem, ela representa a qualidade de ser consciente, de negar, de transcender. Ela define a possibilidade da pessoa se recusar como coisa e se projetar para além de algo ou de si mesma. Sartre afirma que o homem está condenado a ser livre, o homem não é livre para abandonar sua liberdade (Angerami-Camon, 2007).

É da liberdade que provém o sentimento de angústia, o homem precisa viver com o vazio do nada. Silva (1997) comenta que é através da liberdade que o nada se manifesta, e para isso, ela provoca no homem o sentimento de angústia. A angústia representa o dar conta da existência do nada, que é futuro dependente das ações possíveis, mas que ainda não-são, é ser um eu que não-é. O homem horroriza-se diante deste vazio, desta indeterminação e a descoberta ainda mais angustiante é que este vazio não está fora de nós e sim em nós mesmos. Segundo Angerami-Camon (2007), a angústia é o objeto mais elementar de sofrimento da existência, ela é a particularidade da condição humana.

A respeito do suicídio, Angerami-Camon (1986) afirma que nada é tão ameaçador à vida do homem do que ele mesmo. Atrás de seu projeto de vida está, dissimulado, seu projeto de morte. Citando Sartre, expõe que o homem é o que ele se fez e se faz ser. O homem é o responsável pela destruição da sua vida 
de forma consciente e real, para decidir pelo fim de sua existência o homem precisa se conceber, se reconhecer como outro. A pessoa que tenta o suicídio, muitas vezes, não busca a morte como o desaparecimento real do mundo, o suicídio é mais uma tentativa de resolver conflitos e sofrimentos nos quais a existência se encontra, de libertar-se de uma ausência intolerável, a morte é apenas uma consequência. Com o suicídio, a pessoa manifesta a verdade que definiu seu fracasso social, não há lugar para esta pessoa. Com a morte, isenta o seu ser da frustração de ser.

$\mathrm{O}$ ato de suicidar-se está envolvido por desespero, perante uma força incapaz de conceber razão e significado para a vida. Em meio a esse desespero e sofrimento, o suicídio justifica-se na destrutibilidade presente no que se consolida um ato extremo de desespero. Na medida em que se manifesta como um modo de ser da consciência, o suicídio é a apreensão de algo, que é "eu mesmo". O desespero humano tem no suicídio uma das manifestações mais extremas de determinação e o ato de suicidar-se precisa ser compreendido a partir da realidade única do ato, que é a realidade da vida da pessoa em sua manifestação existencial (Angerami-Camon, 1986).

\section{Possibilidades clínicas em Heidegger: a alienação do poder-ser}

O poder-ser aqui tratado explicita a amplitude do conceito de saúde em Heidegger. Nesta leitura, o adoecer remete à privação do ser diante da abertura às possibilidades que, de maneira geral, se mostra contingente aos padrões cotidianos de cada um (Nogueira, 2008). Dentro dessas perspectivas de aniquilação e restrição da variedade e, principalmente, legitimidade comportamental, a atuação clínica fundamentada em Heidegger encontra amparo e constrói suas propostas.

Toda a leitura do adoecimento, colocando-o num processo gradual que percorre o padecimento, de acordo com Nogueira (2006), demanda uma compreensão do indivíduo na sua singularidade, dentro da sua idiossincrasia ontológica, uma vez que o padecer é um processo singularizador. $O$ padecimento acaba por singularizar o indivíduo porque graças a estas particularidades situacionais ele é aceito e reconhecido como ser incomparável a qualquer outro; ainda que o custo seja a restrição dos seus projetos existenciais e do seu horizonte de possibilidades. $\mathrm{O}$ dasein enfrenta então duas diferentes condições diante do adoecimento: de um lado permite a vivência deste ser único na extremidade de suas angústias, por outro, sugere uma expectativa deste ser pelo retorno ao modo não-modificado de estar no mundo. 
Nessa segunda escolha, o ser opta por retornar à medianidade e à tranquilidade do conhecido.

Vivenciar saudavelmente as possibilidades do dasein consiste em, inequivocamente, assumir responsabilidades. Vejamos o que Nogueira (2008, p.286) nos diz a respeito:

\begin{abstract}
A abertura brinda ao dasein seu poder-ser no mundo, num horizonte de temporalização que abrange o passado, o presente e o futuro. Faz parte da história do dasein como humanidade, mas é algo a cujo significado cada homem deve responder. Como ser lançado ao mundo, que se compreende a si mesmo em sua relação com os entes enquanto entes, na sua totalidade, o dasein se confronta com o desafio de assumir por inteiro essa abertura que essencialmente lhe pertence.
\end{abstract}

Aqui encontramos então espaço para justificar o posicionamento heideggeriano a respeito da função analítica, conforme o autor (Heidegger citado por Moreira, 2010), esta se traduz na possibilidade de se evidenciar a unidade primeira da função da capacidade compreensiva. No processo de desvelar, a análise objetiva capta o todo de um conjunto de condições ontológicas do ser, efetuando um retorno à conexão de um sistema que representa uma estrutura composta por unidades elementares menores articuladas. Complementa ainda Feijoo (2002) que, em um entendimento heideggeriano, o ato de autorizar-se ao processo psicoterápico representa em si a busca do ser pela recuperação da liberdade e da flexibilidade em suas relações com o mundo.

\title{
Possibilidades clínicas em Sartre: o existente e o mundo
}

Em sua teoria, Sartre confronta a perspectiva subjetivista em que a solução está no mundo interno da pessoa, a perspectiva mentalista, que vê o mundo interno em uma estrutura mental independente e a concepção metafísica do psiquismo. A dialética é incluída na Psicologia e a subjetividade e o sujeito tem seu lugar (Schneider, 2006). Para Sartre (2010), o corpo tem um caráter duplo, ao mesmo tempo ele é objeto no mundo e também a experiência vivida imediata da consciência. A consciência não só projeta significações afetivas no mundo, mas também vive o mundo novo que acaba de constituir.

O homem e o mundo são um ser entrelaçado. Sartre (2010) relata que o homem é um ser do mesmo tipo que o mundo, portanto, concordando com 
Heidegger, afirma que as noções de mundo e de realidade-humana são inseparáveis. Sendo assim, a Psicologia não deve pretender alcançar a realidade-humana, se é que ela existe. Para estabelecer os limites dos fenômenos emotivos e defini-los o psicólogo deve dirigir-se à experiência.

A finalidade da intervenção na Psicoterapia Existencial é a construção mais autêntica e significativa da existência, auxiliando a pessoa a escolher-se e agir com maior autenticidade e responsabilidade na construção de seu-mundo. A proposta da Psicoterapia Existencial Sartriana é de compreender o existente por meio das diferentes maneiras em que a consciência se relaciona com o mundo, com os outros e consigo mesma e como a pessoa tenta evitar a angústia do confronto com sua liberdade, tendo como finalidade identificar as escolhas que a pessoa faz para se tornar pessoa, qual é seu projeto existencial. A existência concreta do indivíduo é analisada, ela é vista como a expressão de um projeto concreto e entende-se que, ao questioná-la, a pessoa se compreende e possibilite a mudança. Para isso, é utilizado o método hermenêutico, que tem como objeto o modo como a pessoa constitui sua relação com o mundo e o seu projeto existencial que dá o sentido, os fenômenos psicológicos estão em consonância com o projeto. Não se pretende conhecer o mundo que a pessoa projeta, mas sim, conhecer como a pessoa se projeta no mundo e lida com sua liberdade de escolha (Teixeira, 2006).

Pelo exposto, percebe-se no posicionamento do psicoterapeuta clínico com base na Fenomenologia-Existencial (seja ela ancorada em Heidegger, seja em Sartre) um investimento no sentido de desnudar com o indivíduo as possibilidades de uma existência autêntica. Em estudo realizado com terapeutas de diferentes abordagens acerca do tratamento do tentador de suicídio, Senna et al. (2004) constataram que sobressaiu no relato dos terapeutas fenomenológicos a preocupação em respeitar a decisão do cliente, seja ela qual for, por ser representativa de sua liberdade de escolha. Os terapeutas fenomenológicos, no estudo citado, relataram se voltar para o sentido dado ao ato de suicidar-se e à experiencia vivencial do tentador, no decorrer do processo psicoterápico.

\section{Considerações Finais}

O ato do suicídio suscita diferentes julgamentos e uma ampla gama de leituras superficiais criadas no coletivo, nas instituições. A relevância de uma aproximação compreensiva, aqui representada pelo enfoque FenomenológicoExistencial, está no desvelamento dos sentidos mais legítimos desse fenômeno, 
sabendo-se que a ele atrelados estão o ser e sua existência, o ser e seu mundo. Como unidade, como o ser-aí que é ainda um projeto de vir-a-ser.

Evidencia-se a necessidade de humanizar o atendimento prestado pelos profissionais de saúde à pessoa que tentou o suicídio, uma vez que hoje esta atenção se mostra permeada por desprezo, aversão, agressividade e preconceito (Sampaio \& Boemer, 2000). Angerami-Camon (1986) acrescenta ainda que o engajamento na luta contra a coerção e as condições de restrição das possibilidades de existência representa uma potencial abertura na busca pela dignidade existencial, podendo posteriormente culminar em desdobramentos sociais mais amplos.

O viés adotado neste artigo foi o da constrição do ser enquanto conjunto de circunstâncias capazes de retirar, reduzir ou alienar seu horizonte de possibilidades. O conceito cerne foi, portanto, o da liberdade. Em uma leitura heideggeriana o ser está no mundo em uma relação de copertença, uma existência inautêntica seria resultante de uma entrega à vulgaridade das massas em detrimento das singularidades, em contrapartida, uma existência autêntica corresponderia a uma noção de responsabilidade e de finitude do ser. Ser saudável é poder-ser livre em um mundo de escolhas flexíveis.

Em Sartre desnudamos a gravidade da situação do ser que é aniquilado pelas limitações de suas escolhas. Este sempre poderá escolher, não as restrições das suas condições existenciais, mas o seu modus operandis de enfrentar os infortúnios, o horror, a frustração. Diante da liberdade é que o homem constata o nada, que emerge geminado à angústia e direciona seu olhar para este vazio que é ele, é, portanto, o olhar para si. O sentimento de sofrimento e desespero diante de não se conceber razão ou significado para a vida envolve os atos destrutivos que se relacionam com o suicídio. Suicidar-se não diz respeito a perder algo (a vida), mas sim a libertar-se da ausência que se sente.

Nas possibilidades clínicas, Heidegger e Sartre enfatizam a singularidade do ser, a liberdade e a responsabilidade pelas escolhas. Em Heidegger está presente o padecimento, que diferencia a pessoa, porém a restringe de seus projetos existenciais, visto que esses projetos se constituem das escolhas que as pessoas fazem para se tornarem pessoas.

Heidegger fala sobre assumir responsabilidades, a pessoa pode-ser no mundo, ela tem abertura para suas escolhas e vive o desafio deste poder-ser, cada pessoa é responsável pelo que faz com suas possibilidades. Sartre afirma que o homem é condenado a ser livre e o confronto com essa liberdade causa angústia, a pessoa faz suas escolhas e responde por elas, seu projeto existencial dá sentido às relações com o mundo e envolve os fenômenos psicológicos. 
A visão de realidade humana e de mundo é a de algo entrelaçado, um está intimamente ligado ao outro e são inseparáveis, para compreender os fenômenos psicológicos a experiência é que deve ser focalizada. A intervenção psicoterápica possibilita a construção autêntica e significativa da existência, a pessoa deve compreender-se na construção de seu mundo. No pensamento heideggeriano, a pessoa em psicoterapia busca a recuperação de sua liberdade e de uma melhor relação com o mundo, em Sartre compreende-se que a psicoterapia visa possibilitar a identificação das escolhas, o conhecimento da pessoa em suas relações com o mundo e com a liberdade de escolha.

Sob um ponto de vista existencialista, a psicoterapia é o locus de recuperação do pensamento meditante, o ser é chamado a refletir sobre os sentidos de seu mundo como modo de prevenir a sua perda no universo da impessoalidade e da publicidade. Faz-se um convite para que este ser resgate sua singularidade (Feijoo, 2002). Angerami-Camon (1986), sobre seus trabalhos no Centro de Estudos em Existencialismo e Psicoterapia com pacientes potencialmente suicidas, ressaltou ter percebido uma eficiência relevante das intervenções voltadas para minimizar o estreitamento social a que estas pessoas eram submetidas. Esse é um caminho promissor, portanto, para a intervenção do terapeuta que se depara diante do fenômeno suicídio. $O$ desvelar das possibilidades de poder-ser dentro de suas singularidades, sem perder-se na medianidade, sem esconder-se de si mesmo.

À guisa de conclusão sugere-se ser coerente a consideração do constrangimento do ser e da alienação existencial como hipóteses Fenomenológico-Existenciais para o ato do suicidar-se. Nos fundamentos de Heidegger encontra-se a referência à marginalização da liberdade de escolha do ser, que perde-se no impróprio, sendo levado pelo das Man. No que concerne à leitura sartriana aqui desenvolvida, pôde-se igualmente encontrar referências à perda da liberdade como fator contribuinte para a impossibilidade de continuar sendo no mundo. O tentador do suicídio é então constrangido diante da limitação de sua abertura de possibilidades, terreno no qual a alienação existencial fértil se faz. Assim, nas palavras de Angerami-Camon (1986), o suicídio se apresenta como uma tentativa de resolver conflitos e sofrimentos nos quais a existência se encontra, de libertar-se de uma ausência intolerável, e neste contexto a morte é apenas uma consequência. 


\section{Referências bibliográficas}

Angerami-Camon, V. A. (1986). Suicídio: uma alternativa à vida, uma visão clínica-existencial. São Paulo: Traço. (2007). Psicoterapia existencial. São Paulo: Thomson Learning.

Araújo, P. A. (2007). Nada, angústia e morte em Ser e Tempo de Martin Heidegger. Revista Ética e Filosofia Política, 10 (2), 1-15, dez.

Binswanger, L. (1977). El caso de Ellen West: Estudio antropológicoclínico. In: May, R., Angel, E. \& Ellenberger, H. (Eds.), Existencia, pp. 288-434, Madrid, España: Gredos.

Feijoo, A. M. L. C. (2002). A psicoterapia em uma perspectiva fenomenológicoexistencial. In: Camon, V. A. A. Psicoterapia Existencial. São Paulo: Thomson.

Figueiredo, L. C. M. (2003). Matrizes do pensamento psicológico. 10. ed. Petrópolis - RJ: Vozes.

Forghieri, Y. C. (2004). Saúde existencial: vivência a ser periodicamente reconquistada. Boletim Academia Paulista de Psicologia, 24 (1), 46-57, janabr.

Marques, V. B. (2010). O mesmo, os outros e o “eles". Trans/Form/Ação. 22 (2), 129-142.

Mello, M. F. (2000). O suicídio e suas relações com a psicopatologia: análise quantitativa de seis casos de suicídio racional. Cadernos de Saúde Pública, 16 (1), 163-170, jan-mar.

Moreira, V. (2010). Possíveis contribuições de Husserl e Heidegger para a clínica fenomenológica. Psicologia em Estudo, 15 (4), 723-731, out-dez.

Moreira, V.; Cruz, A. V. H.; Vasconcelos, L. B. (2005). O caso Ellen West de Binswanger: fenomenologia clínica de uma existência inautêntica. Revista Mal-Estar Subjetivo, 5 (2), set.

Nogueira, R. P. (2006). Uma análise existencialista da saúde. Interface Comunicação, Saúde, Educação, 10 (20), 333-45, jul-dez. 
. (2008). Estresse e Sofrimento: uma interpretação Heideggiana. InterfaceComunicação, Saúde, Educação, 12 (25), 283-93, abr-jun.

Sampaio, M. A. \& Boemer, M. R. (2000). Suicídio - um ensaio em busca de um des-velamento do tema. Revista Esc. Enf. USP, 34 (4), 325-31, dez.

Sartre, J-P. (2010). Esboço para uma teoria das emoções. Porto Alegre: L\&PM.

Schneider, D. R. (2006). Liberdade e dinâmica psicológica em Sartre. Natureza Humana, 02 (08), 283-314, jul-dez.

Senna, A. C. B. M.; et al. (2004). Suicídio - diversos olhares da Psicologia. Boletim de Iniciação Científica em Psicologia, 5 (1), 77-92.

Silva, C. G. (1997). Liberdade e consciência no existencialismo de Jean-Paul Sartre. Londrina: UEL.

Teixeira, J. A. C. (2006). Introdução à psicoterapia existencial. Análise Psicológica, 24 (3), 289-309.

Werle, M. A. (2003). A angústia, o nada e a morte em Heidegger. Trans/Form/Ação. 26 (1), 97-113. 